\title{
Development of a Framework for Teaching L2 English as a Situated Practice in Malawi
}

\author{
Mapopa Sanga ${ }^{1, *}$ \\ ${ }^{1}$ Department of Excellence in Teaching and Learning, Southwestern Oklahoma State Universitity, USA. \\ *Correspondence: Department of Excellence in Teaching and Learning, Southwestern Oklahoma State Universitity, \\ 100 Campus Drive, Weatherford, OK 73096, USA. E-mail: mapopa.sanga@swosu.edu
}

Received: June 29, 2016

Accepted: July 13, 2016

Online Published: July 22, 2016

doi:10.5430/ijelt.v3n2p58

URL: http://dx.doi.org/10.5430/ijelt.v3n2p58

\begin{abstract}
In response to the demands of 21 st century teacher preparation practices, this developmental study was instigated by the need to employ appropriate strategies in the teaching of English as second language (L2) in Malawi. Using situated cognition theoretical construct as a basis, a framework for teaching L2 English as a situated practice was created. The development process was guided by views and practices of English methodology faculty members in Malawi's five secondary school teacher training institutions.

The study was conducted in three phases, firstly, analysis, where eight English methodology faculty members from Malawi's five institutions of higher learning were interviewed on the strategies they use to train pre-service secondary school teachers of English. Secondly, development, where the framework was created based on results from the analysis phase, and thirdly, evaluation and revision where the framework was reviewed and validated by a situated cognition expert and three of the faculty members who were interviewed in Malawi. Taking into consideration input from these four evaluators, the framework was then revised.
\end{abstract}

Keywords: English as an L2; situated cognition; Malawi; developmental research; framework

\section{Introduction}

Situated cognition is an important construct on the nature of learning. The theory delineates vital inferences for the design and development of vibrant classroom teaching, including the design of technology or computer based instruction. It is also a construct that underscores and upholds real and authentic learning. In a situated learning setting, learning of skills and knowledge occur in contexts that reflect how that knowledge is gained and applied in everyday life (Altalib, 2002; Collins, 2006; Lave \& Wenger, 2003). As Resnick (1987) observed, the separation between knowing and doing customarily has been the attribute of school and university learning. Herrington and Oliver (2000) extended this view by contending that the emphasis in school and university has been on extracting important principles, concepts, and facts and teaching them in a decontextualized form.

While some researchers and thinkers still argue that context in which learning takes place is secondary to the actual learning process, Brown, Collins, and Duguid (1989) revealed through their research on learning that what is being learned cannot be separated from the context in which it is learned or applied; rather, it is an integral part of what is learned. The situated cognition theoretical construct proceeds on the latter body of knowledge and its proponents contend that human actions are dependent on the context in which they occur. So in short, situated cognition emphasizes the importance of contextualizing learning in authentic learning environments where sound activities related to the concepts being taught are provided to the learner, and where collaborative construction is supported, reflection is promoted and scaffolding complements the process of making teaching and learning more meaningful (Brown et al., 1989; Cognition \& Technology Group at Vanderilt [CTGV], 1990; Collins, 2006; Collins, Brown \& Newman, 2007).

Numerous studies have been conducted on situated cognition addressing authentic learning in various contexts. Such studies have demonstrated that learners do show elaborate skills in practical contexts unlike in formal tests. They have also examined the likelihood of shifting the indicator and assessment of proficiencies from one context to 
another and of regarding them in a decontextualized way. Other studies conducted in second language acquisition contexts have found that there is need to go beyond simply proposing activity as a contextual occurrence but to also recognize that cognitive processes in general and language learning especially, are publicly organized, socio-interactionally configured, and contextually dependent (Brown, et al., 1989; Lave 2008; Mondada \& Doehler 2004).

While some studies have examined the philosophy in situated cognition as applied in second language learning, the literature shows that no such type of studies have been conducted in an African context and that includes Malawi. Also, in certain contexts, such studies have been conducted in countries where the second language being learned is not the official language. To that end, it was felt that there was need to study this pedagogy in the context of teaching and learning of second languages in Africa. It is a practical thing to point out that much as languages such as English are mostly learned as L1 (first language) in the west, they are not only learned from an L2 (second language) perspective in Africa but also as foreign, imported languages. This leaves a gap in the literature for the conduct of studies in situated cognition and second language learning in African countries like Malawi where a second language can also be the official language.

\subsection{Need for the Study}

Malawi is a developing southern African nation that came under British colonial leadership in 1891 and attained independence in 1964. From a language perspective, more than 14 local languages are spoken in Malawi and in addition, five other foreign languages are taught and spoken in different proportions (Kamwendo, 2007a, 2007b; Kayambazinthu, 2008a, 2008b; National Statistics Office [NSO], 2008; Nave, 2009).

Apart from Chichewa which is the national language and 13 other local languages, Malawi has English as the main official language. All the three arms of government mechanism (executive, legislature and judicial) use it as the official medium of their business. This blends in well with the fact that English is the world lingua franca. It is a requirement in the constitution for instance, that members of parliament should exhibit thorough fluency in written and spoken English since the language is the only medium of proceedings in the august house. For this reason, to contest in parliamentary elections, candidates have to be holders of the Malawi School Certificate of Examinations (M.S.C.E) with a pass in English which is already a requirement for attainment. In education, English is the principal language, it is taught as a subject from grade one in elementary school through university. It is also a medium of instruction from grade one. School certificates are not awarded in Malawi if a candidate gets a fail in English and university entrance examinations have a competence test component in English. Despite this trend, standards of the language have been observed to be going down (Bwanali, 2002; Kamwendo, 2008; Kayambazinthu, 2008a; United Nations Educational, Scientific and Cultural Organization [UNESCO], 2003). Problems in the deterioration in standards of the English Language have been noted at various levels and forums. It has generally been noted for example, that despite passing the subject well in secondary school, when students come to university or go into work places, they fail to express themselves clearly in the language (Bwanali, 2002; Kamwendo, 2008). This demonstrates that despite performing well in learning contexts, learners of the language apparently fail to transfer that knowledge to performance contexts.

A study by the Ministry of Education on the performance of students in formal examinations indicated that over the last seventeen years or so, the pass rate of the English language in secondary schools has significantly gone down resulting in many students failing to acquire certification (Ministry of Education [MOE], 2014). From the author's experience in teaching English courses at university level where he had also supervised pre-service teachers, it was noted that there was need to improve the pedagogical approach that is currently in practice in schools so that it promotes authentic learning. For example, it was noted that teaching of English as a second language was mostly done using strategies that do not make learners active participants in what they learn. Mostly, students are involved in rote learning and are given minimal opportunity to practice speaking and writing in the most authentic, creative and meaningful manner. Instead, students go through a series of examinations that mostly test for proficiency in the language rather than involving them in activities that would engage them in meaningful contexts. So, there appears to be need to employ appropriate strategies in the teaching of English as an L2 so that students learn concepts in a way that they would easily be able to use them in the real world. To that end, the present study responded to the need to improve pedagogical practices in the English as an L2 classroom in Malawi. Against this background, the author held the belief that use of situated cognition strategies in the English as an L2 classroom in Malawi would have a positive impact on the teaching and learning of various skills in the language.

\subsection{Purpose of the Study}

The purpose of this study was to develop a framework for teaching second language English as a situated practice. It 
was planned that the framework would be used by university faculty members in Malawi to train pre-service teachers to employ a contextualized language instruction approach in the teaching of topics in English language and grammar in a second language context. The study employed the following three phases: Analysis, development and evaluation and revision.

\subsubsection{Phase One: Analysis}

This phase involved interviewing eight conveniently sampled faculty members from five teacher training institutions of higher learning in Malawi (Fraenkel, Wallen \& Hyun, 2015; Russ-Eft \& Preskill, 2009). The interviews sought to seek their views on the strategies they use to train pre-service teachers of English.

\subsubsection{Phase Two: Development}

Based on the results from Phase One, a framework for teaching English as a situated practice in Malawi was created. Developmental research studies involve the production of knowledge with the ultimate aim of improving the process of instructional design, development, and evaluation. Such research is based on either situation-specific problem solving or generalized inquiry procedures (Richey \& Klein, 2010). The prototype was designed to reflect the features of situated cognition derived from the literature and indicate how to operationalize that for L2 English instruction in Malawi.

\subsubsection{Phase Three: Evaluation and Revision}

The study employed a formative approach to evaluate and revise the product (Richey \& Klein, 2010). One situated cognition expert from a state university on the northern part of the United States examined the framework for conformity with the construct. The framework was also evaluated by three of the faculty members interviewed in Phase One and it was revised based on input from these evaluators.

\section{Analysis}

Analysis involved interviewing eight conveniently sampled faculty members from five teacher training institutions of higher learning in Malawi. Using semi-structured open-ended questions, the selected faculty members were interviewed. The questions basically sought to seek their views on the strategies they use to train pre-service teachers of English. The interviews did not actually take a full needs assessment approach where the researcher would have gone there with a blank slate and planned to learn everything from the interviewees (Witkin \& Altschuld, 2007). Rather, the researcher went there with principles of situated cognition in mind from the literature, and latterly related such strategies with what was obtained from the interviews. Considering that situated cognition is a new concept in Malawi, the researcher conveyed the description of the construct in the interviews using simple academic language rather than technical terms. While review of syllabi initially provided the researcher with an impression of the strategies the faculty members used to train pre-service teachers, the actual interviews provided opportunity to explore a detailed account of what exactly went on in class.

\section{Data Analysis and Results}

Data collected from interviews with eight Malawian English methodology faculty members produced eight transcripts which were qualitatively analyzed in NVivo software. In a single iteration, the transcripts were coded in NVivo in line with the purpose of the study. A total of 115 codes were generated as a result of this process. Whole text analysis was used to examine the continuous text contained within the transcripts. This technique requires the researcher to fully understand the purpose of his or her study to enable them study the data continuously in order to identify specific codes. This procedure for analysis was developed by Glaser and Strauss (2012) and Strauss and Corbin (2015). From the theme: "Strategies for training pre-service secondary school teachers of English in Malawi", seven categories were derived. These were: Teaching goals, teaching philosophy and theoretical beliefs, instructional strategies for training pre-service teachers, instructional strategies for use in secondary schools, assessment strategies, advantages of using an authentic learning framework and potential challenges for using an authentic learning framework. These categories provided the basis for discussion of the responses obtained from the eight English methodology faculty members. These categories were then discussed with close reference to the data contained in the transcripts. Results from this phase were used to guide the framework development phase in the following ways: (1) They assisted in deciding what content to include in the framework; (2) they helped in justifying what the framework would be used for, and (3) they would tell whether the framework would replace current strategies being used or largely complement the strategies. From the analysis of the data, numerous issues arose that would guide the 
framework development phase. These issues are presented in summary below, through the lens of situated cognition construct.

\subsection{Framework for Teaching L2 English as a Situated Practice Operationalized}

Based on the themes identified from interviewing English methodology faculty members in Malawi, and improved upon by suggestions from an expert reviewer and users, a framework for teaching English as a second language using situated cognition strategies was created. The framework would be used by university faculty members to train pre-service teachers of English.

In an effort to break the conventional school culture, the situated activities have been designed to encourage instructors to create environments that involve moving students from learning-about something to learning-to-be something (Brown, 2006; Wenger, 2008). Also, while these situated activities would be implemented in the English classroom in Malawi and not outside it, there is an understanding that there is ongoing communication infrastructure or array of networks that Malawian students, their families, the instructors and indeed everyone in the target culture belongs to, or has some access to. For example, ideally, schools in Malawi have committees comprising of selected parents of students who act as a link between a particular school and the rest of the community. And so in essence, the framework takes a deliberate approach to assist students to acquire knowledge that will be easy to use outside of the classroom. As Krajcik and Blumenfeld (2006, p.319) contended, "when learners acquire information through memorization of discrete facts that are not connected to important and meaningful situations, the superficial understanding that results is difficult for students to generalize to new situations".

Table 1. Issues that Guided Framework Development Phase

- Faculty members put forward three philosophical or theoretical beliefs reflected in teaching; constructivism, communicative approach, teaching and learning being contextual.

- While there is no single constructivist theory of instruction, researchers in the field of instructional technology among others, articulate various aspects of a constructivist theory (Driscoll, 2005).

- As a construct, situated cognition postulates learning to take place in familiar contexts rather than unfamiliar contexts (Brown, Collins \& Duguid, 1989).

- So, while constructivism is about constructing new knowledge from experience, situated cognition goes a step further by focusing on meaning making in the right context of the knowledge.

- The communicative approach is not only in line with requirements of the Ministry of Education in Malawi for the teaching L2 English, it is also the popular pedagogy in teaching second languages in the 21st century (MOE, 2014; Richards \& Rodgers, 2001).

- While situated cognition focuses on authentic learning, the communicative approach focuses on communicative proficiency rather than the command of structures (Brown, Collins \& Duguid, 1989; Littlewood, 2009).

- Faculty members held belief that teaching and learning is contextual. This is in line with the philosophy underlying situated cognition.

- Lecture was dominant strategy for training pre-service teachers of English. Others included group work, question and answer, recollection, debates, pair work, role-plays, demonstration and microteaching.

- Out of these, role-plays, debates and group work, especially small groups, are situated cognition strategies (Bonk \& Reynolds, 2007; Van Ments, 2007).

- Faculty members disclosed they prefer using learner-centered strategies. However, they pointed to large class sizes as a hindrance to learner-centered teaching.

- An authentic learning approach would also likely be hindered by large class sizes and this would be put into consideration while developing the final deliverable.

- Faculty members expected students to model use of pair work, role plays, group work, question and answer, presentations, projects, conferencing, lecture, debates, simulation and field trips for use in secondary schools.

- They emphasized that while imparting any of these strategies, students are encouraged to integrate 
the four language skills namely; listening, reading, writing and speaking.

- Although Choi and Hannafin (1995) argued that authentic activities are not simulated tasks, meaning that they are real, it is naturally not easy recreate the real world in the classroom.

- To that end, the framework would be designed to enable instructors and learners to simulate real world activities in the classroom.

- Faculty members pointed out that even though student teachers are equipped with good strategies prior to teaching practicum, they still faced challenges such as poor mentorship, large class sizes, unmotivated students, scarcity of teaching and learning materials, contrary pedagogies and teaching for examinations by established teachers.

- The situated cognition approach would most likely face similar challenges.

- Faculty members put forward numerous strategies they use to assess students' work namely; formal examinations, desk research, practice teaching in demonstration schools, group projects, presentations, microteaching, peer teaching, essay writing, lesson plan development, evaluating teaching strategies.

- Assessment in situated cognition discourages "teaching to the test" because when students realize that are being tested on the ability to recall, they simply memorize information which consequently decontextualizes their knowledge (Choi \& Hannafin, 1995).

- Strategies such as desk research, group projects, presentations, microteaching, peer teaching, essay writing, development of lesson plans ought to be conducted seamlessly with teaching and learning rather than as separate activities for them to be deemed situated learning strategies.

- Faculty members pointed out that assessment by desk research becomes a challenge in the sense that, mostly, students can evaluate a theory but fail to put it into practice which is quite contrary from what situated cognition postulates.

- Lack of participation by students suggested a challenge to implementing some teaching strategies. According to situated learning, non-participating learners would fail to close gap between learning and use.

- Pre-service teaching in demonstration schools and evaluation of strategies employed in schools are in line with situated learning practice.

- Suggested advantages for using an authentic learning framework were; framework would enable teachers to understand how to put language rules into use, would enable students practice what is realistic, would enable faculty members find solutions to problems faced by students since it takes context into consideration, would minimize teaching for examinations, would promote teaching and learning which reflects what will happen outside the classroom, would reconcile language with communicative ways of teaching, and since it takes a bottom-up approach it would very likely succeed. These would, in essence, pave way for its development and eventual implementation.

- Potential challenges framework would face included; problem of lack of time and space, old timers mostly reluctant to embrace change in Malawi schools, school system itself is examination oriented, willingness of the Ministry of Education to implement the framework would be an issue, would prove expensive since it means taking students to places for example the court, hospital, and others, it might demand a paradigm shift in terms of teaching and learning materials.

- It must however be pointed out that the situated cognition pedagogy would not necessarily demand taking students to different places for lessons; rather, effort would be made to simulate activities from the real world. 
Table 2. Strategies for Situated Task to Create Authentic Context that Reflects the Way Knowledge Will be Used in Real Life

Situated Task: Provide authentic context that reflects the way knowledge will be used in real life (Brown, Collins \& Duguid, 1989; Collins, 2006; Gabrys, Weiner, \& Lesgold, 2007; Harley, 1993; Herrington \& Oliver, 2000; Resnick, 1987, Winn, 1993, Young, 1993).

Example: Teaching tenses of the English Language

- Teaching grammar in context can be a challenge to most practitioners (Swick, 2014; Weaver, 2006).

- To teach Past Tense in English, begin by asking students to cite occasions tense has been used and why. Let students recollect scenarios, citing specific examples, why they thought the past tense was used. Learners draw experiences from everyday things like health, nutrition, farming, child care, religion, safety needs, vocational activities, politics. Class provides input to examples.

- Instructor introduces familiar stories from Malawian literature and asks students to identify them.

- Instructor reads out familiar story set in the past.

- At second reading, instructor asks some students to read out story to fellow students.

- From story, students take notes after which individuals present to class, past tense excerpts from it.

- Instructor discusses with class past tense examples identified, providing feedback where necessary.

- Instructor recaps by discussing formal and informal real life occasions the tense is typically used. Students cite examples from the context of their day to day life.

Engage students in a field project to look for other stories from other literary genres, identify use of the tense for class presentation. Learners encouraged to work on project with family members and other community members.

Same structure can be used to teach other tenses in English.

\section{Instructor Role}

Encourage learners to draw examples from everyday life, stimulate thinking, facilitate class discussion, provide feedback as needed, thrash out modalities for field project with class.

\section{Student Role}

Cite examples from day to day experiences, participate in story identification, volunteer to read out story to class, present views to rest of class, participate in thrash-out of modalities for field project.

Table 3. Strategies for Situated Task to Promote Reflection

Situated Task: Promote reflection - opportunity for learners to compare with other learners, collaborative groupings of students (Brown, Collins \& Duguid, 1989; Collins 1988; Herrington \& Oliver, 2000).

\section{Example: Teaching writing skills - writing an essay in English}

- In teaching how to write an essay, ask learners to explain importance of developing good writing skills for life outside the classroom. For example, students could state the importance of developing writing skills for different contexts such as health, religion, education, farming, child care, medicine, law, politics. Learners come up with views to discuss with others, instructor provides support.

- Instructor gives class short writing exercise on a stimulating and practical topic. For example, write about their views on the quota system for selecting Malawian students to university.

- Class brainstorms ideas on selected subject, go into individual writing using ideas from plenary.

- After learners complete task, instructor divides class in manageable groups. Learners share structure and content of their essay with group members, receiving feedback from colleagues. 
- Groups present final thoughts to class, instructor provides feedback with class weighing into presentations.

Engage students in a field project to write a different, longer topic. Students encouraged to work on project with family members and other community members.

Use same structure to teach other types of writing in English.

\section{Instructor Role}

Encourage students to draw examples from everyday life, provide feedback to students on views, facilitate class discussion, facilitate formation of groups, supervise group work, provide feedback to groups, thrash out modalities for field project with class.

\section{Student Role}

Share views on writing from everyday life with classmates, brainstorm ideas on writing topic, share written work with others, participate in group discussion, take part in presentations, weigh in to other students' presentations, participate in thrash-out of modalities for field project.

Table 4. Strategies for Situated Task to Promote Articulation

Situated Task: Promote articulation - groups to enable articulation, publicly present arguments to enable defense of learning (Bransford et al., 1990; Collins, 2006; Herrington \& Oliver, 2000).

Example: Teaching speaking skills - speaking in public.

- In teaching speaking in public, engage students in a discussion on occasions that require people to make a public presentations. Students encouraged to draw from speaking occasions in health, nutrition, farming, child care, religion, safety needs, vocational activities, politics, education.

- Instructor leads class into selecting topics from day-to-day-life for public presentation. Allow students to provide input in selecting most stimulating and contentious topics.

- Instructor facilitates formation of an even number of groups and gives directions for holding debates. Let group members confer before staging debates between two groups a time. Each group takes sides on a contentious topic such as pros and cons of allowing Malawian presidents to vie for a third term of office. Let members of two debating groups (at a time) present arguments on their topic, defending their knowledge and beliefs with rest of class being audience.

- $\quad$ Recap by asking learners to come up with challenges they faced during exercise with instructor providing feedback for improvement.

Engage students in a field project to take part in other public speaking events with people in their community and present findings in class.

Use same structure to teach other topics in English language and grammar.

\section{Instructor Role}

Encourage students to draw examples from everyday life, provide feedback to learners on their views, lead learners in topic selection, facilitate group formation, supervise group work, set directions for holding debates, provide after-debate feedback, thrash out modalities for field project with class.

\section{Student Role}

Share views on occasions that require making public presentations, provide views on topics for debates, confer with group members before debates, participate in debates, weigh in to after-debate discussion, participate in thrash-out of modalities for field project. 
Table 5. Strategies for Situated Task to Support Collaborative Construction of Knowledge

Situated Task: Support collaborative construction of knowledge - classroom organization into small groups (Bransford, Sherwood, et al., 1990; CTGV, 1990; Collins et al.,1989; Herrington \& Oliver, 2000; Resnick, 1987; Young, 1993)

Example: Teaching the Passive Voice in English

- To teach the Passive Voice in English, instructor begins by asking students for definition. Learners cite varying definitions from general knowledge, instructor consolidates definitions into correct one.

- Instructor asks students to cite scenarios they have encountered the Passive Voice in everyday life and why they thought it was used. Encourage students to vary contexts across health, religion, politics, vocational activities, religion, farming, nutrition, child care. Class weighs in to individual suggestions.

- Instructor randomly assigns small groups, distributes handout containing two familiar stories properly selected from a local source. Within small groups, students carefully read one story and identify passive voice instances.

- Groups discuss what they find and identify functions of each passive voice expression in story.

- Each group to present to class passive voice expressions they identified from story they read, and functions such expressions play in advancing storyline.

- Recap with a plenary discussion of the functions identified through small group exercise.

Engage students in a field project where they collect passive voice expressions used in different social setups in their community. Students encouraged to work on project with family members and other community members. A list comprising passive voice expressions and contexts used should later be brought to class for presentation and discussion.

Same structure can be used to teach the Active Voice, infinitives, gerunds, tenses, phrasal verbs.

\section{Instructor Role}

Encourage students to draw examples everyday life, assign small groups, provide feedback, monitor progress in groups, facilitate whole class discussion, thrash out modalities for field project with class.

\section{Student Role}

Cite scenarios they encountered the Passive Voice in everyday life, weigh in to other students' suggestions, participate in small group discussions, take part in presentations, weigh in to whole class discussion, participate in thrash-out of modalities for field project.

Table 6. Strategies for Situated Task to Provide Coaching and Scaffolding

Situated Task: Provide coaching and scaffolding - an intricate, open-ended learning environment, collaborative learning (Collins, 2006; Griffin, 1995, Harley, 1993 Herrington \& Oliver, 2000).

Example: Example: Teaching phrasal verbs in English

- Situated learning provides the role of the teacher in coaching by observing students, offering clues and prompts, providing feedback, scaffolding and fading, modeling, as integral to learning (Herrington \& Oliver, 2000).

- To teach phrasal verbs in English, ask students to come up with phrasal verbs they have encountered in everyday life. Students encouraged to cite examples across health, nutrition, farming, child care, religion, safety needs, vocational activities, politics.

- Discuss each suggestion with class and determine if it qualifies as a phrasal verb in the context and purpose it serves. Make relevant corrections where necessary with class. When accurate list is complete, discuss with class how listed phrasal verbs are formed, their meanings and in which other contexts they can be used.

- Instructor asks students to write a page-long story from everyday life that connects the listed 
phrasal verbs.

- Depending on what learners suggest, listed phrasal verbs could include: Burn down, keep up, put up, look up, look for, look forward, write down, team up, and so on (Sroka, 2007).

- Let students write story in pairs. As they write, go round, provide hints on how to construct story using given phrasal verbs. Encourage pairs to be assertive, support pairs continuously, communicate problems being faced by each pair to rest of class and ask for solutions, let learners weigh in to problems faced by other pairs, make sure all concerns are addressed openly and that each pair completes task.

- Let pairs submit written stories. After all write-ups are graded, recap by listing common errors and challenges from the write-ups and wrap up by discussing them with whole class.

Engage students in a field project to collect phrasal verbs used in different social setups in their community. Learners encouraged to work on project with family members and other community members. A list comprising phrasal verbs and contexts in which they were used is later brought to class for presentation and discussion.

Same structure can be used to teach a variety of other topics in English language and grammar.

\section{Instructor Role}

Encourage students to draw examples from everyday life, provide feedback to students on their views, facilitate formation of pairs, support pairs, probe students on problems they face during task, create community feel, ask class for solutions to arising problems, thrash out modalities for field project with class.

\section{Student Role}

Identify phrasal verbs from day to day life, work in pairs to produce write up, be assertive, weigh in to issues faced by other pairs, support other pairs, take part in recap and reflective discussion, participate in thrash-out of modalities for field project

Table 7. Strategies for Situated Task to Provide for Authentic Assessment of Learning within Tasks

Situated Task: Provide for authentic assessment of learning within tasks -assessment seamlessly integrated with activity (McLellan, 1993; Herrington \& Oliver, 2000; Young, 1995).

Example: Using poetry to facilitate vocabulary development

- Assessment can no longer be viewed as an add-on to an instructional design or simply as separate stages in a linear process of pretest, instruction, and posttest. Rather, assessment must become an integrated, ongoing and seamless part of the learning environment (Young, 1993).

- Helping students to develop vocabulary may pose challenge to teachers. A literary genre such as poetry can be used to teach and assess vocabulary development in an authentic context.

- Begin by asking learners to cite examples of words typically used in certain fields in everyday life. For example, learners could cite words typically used in areas such as law, education, religion, politics, farming, vocational activities, health, medicine, child care.

- Randomly distribute to students in groups numerous popular poems in English that are set in varying contexts. Ask students in each group to sample poems distributed to them and select two that that they find appealing. Let students quickly identify new words in the poems and present to class their reasons for selecting the poems and the new words. Allocate maximum points of say 20 for successfully completing this task.

- Students read slowly and between the lines this time, decide in their groups whether each of the two poems' tone is sad or happy one. Learners look for more new words from the poems and also write down meanings of all identified new words in the context of the poems, and without using a dictionary before presenting their written thoughts to class.

- Instructor allocates maximum points of say 20 for successfully completing this task.

- Students briefly discuss what they liked/disliked about the poems, write a brief review of one 
poem, and write another stanza for one of the two poems using relevant vocabulary. Present final write-ups to class for feedback. Allocate maximum points of say 40 for successfully completing this task with a proportional distribution of points across tasks.

- Instructor wraps up by discussing with class challenges encountered, takes questions from students and makes clarifications.

Apart from poetry, other literary genres may also be used to teach and assess vocabulary development.

\section{Instructor Role}

Encourage students to draw examples from everyday life, facilitate group formation, supervise and support students in groups, facilitate progress and completion of tasks, facilitate presentations, facilitate final discussion, take arising questions, assign grades to students on tasks.

\section{Student Role}

Participate in group tasks; brainstorming, poem selection, identifying new words and meanings, identifying tone of poems. Discuss what they liked/disliked about poems, write poem review, write new stanza for selected poem, take part in presentations, weigh in to class discussions.

Table 8. Strategies for Situated Task to Provide Opportunities for Role-Playing

Situated Task: Provide opportunities for role-playing - allow students to characterize and play various roles from content being taught (Blatner, 2002; Van Ments, 2007).

Example: Using role plays to teach tenses in English

- Role-playing exercises can be hard work for the instructor, both in preparation and in execution, but the work tends to pay off in terms of student motivation and accomplishment (Blatner, 2002; Van Ments, 2007).

- To teach the Future Tense in English using role-plays, instructor asks students to cite occasions in which the Future Tense has been used in day-to-day life. Contexts could include health, nutrition, politics, vocational activities, child care, religion, farming.

- Let class weigh in to suggestions from individual students with instructor facilitating discussion.

- Instructor briefs class on a role-play to be conducted to teach the Future Tense. Instructor divides class into groups, explains to group members that class will (for example) simulate the Malawi Parliament in the role play. Instructor briefs learners on the setting of the role-play, in this case, simulate parliament sitting with members from government side answering questions from opposition side about projects that the Malawi Government pledged to complete for the people of Malawi.

- Instructor explains that a non-scripted play will be used to run this theme with conflict being created where members from the Government side make pledges and opposition members come in arguing that Government seldom fulfills pledges.

- Instructor further advises students to use the Future Tense as much as they can throughout each play.

- Instructor explains that the Future Tense in English comes in four forms and that all forms can be used (Loberger, 2009; Swick, 2014). These forms are: Simple future (will and be going to), future continuous tense (will be and present participle), future perfect tense (will have plus past participle or be going to plus past participle) and the future perfect continuous tense (will).

- Allow group members to allocate characters to one another with instructor giving goals to be achieved by each character in play. Make sure each character understands their goal very well as they go into role-playing.

- Instructor clearly outlines expectations from participants. Emphasizes need to use the Future Tense at every opportunity.

- Let groups perform one after another, with those not performing taking notes on the performance of those on stage. 
- After each group performs, let learners debrief one another on their use of the Future Tense from the notes they took. Instructor wraps up with a reflective discussion.

Engage students in a field project where small groups conduct role plays to practice use of other tenses in different settings with family members and other people in their community. Make a log sheet of lessons learned and challenges faced during project for later presentation in class.

Same structure can be used to teach other tenses and indeed any other topic in English language and grammar using different themes and setting of the role-plays.

\section{Instructor Role}

Facilitate class discussion, brief class on role-playing a non-scripted play, facilitate formation of groups, brief learners on forms of the Future Tense, run performances, facilitate peer debriefing, facilitate final reflective discussion, thrash out modalities for field project with class.

\section{Student Role}

Participate in initial discussion, take part characters allocation, take part in role-play performances, take notes, take part in peer debriefing, take part in final reflective discussion, take part in thrash-out of modalities for field project.

\section{Summary and Observations}

\subsection{Summary}

In the development of the framework for teaching L2 English as a situated practice in Malawi, an in-depth review of the literature related to the research problem was conducted and a criterion for the study, based upon seven characteristics of situated cognition theory was used as a basis for operationalizing seven tasks. A template-like structure has been delineated that instructors would use to train pre-service teachers of English. From English as an L2 perspective, development of the framework was guided by views of English methodology faculty members from Malawi's five teacher training institutions. Example topics from Malawi secondary school English language and grammar curriculum have been used to illustrate the structure.

As Richey and Klein (2010) observed, in the instructional design process, many expert review studies collect data directly from persons serving as subject matter experts. The present framework was evaluated and validated by a situated cognition expert and three of the eight English methodology faculty members interviewed at the analysis stage. This was done to align it with the situated cognition construct and practicality in the Malawian English as an L2 classroom. From the feedback, revisions were made to the prototype to produce the present artifact.

It was planned from the onset that the framework would be used by university faculty members in Malawi to train pre-service teachers to employ a contextualized language approach in the teaching of topics in English language and grammar. It must however be pointed out that being a framework and not a lesson plan, it would be important for practitioners to study it wholly and embrace the philosophy that it advocates, and apply it in training pre-service teachers of English rather than use it as a step by step guide in teaching. It is expected that English methodology faculty members would study the framework and use it to train pre-service teachers from the perspective of what would be happening in the secondary school English classroom. To that end, it (the framework) delineates templates that show exactly what a teacher-in-training would be required to do in a classroom situation including roles that students would also be required to perform. So, university English methodology practitioners in Malawi would essentially assume the new pedagogy to help them improve upon strategies they have been using to train English teachers.

\subsection{Implications}

The present study goes in line with current trends in the field of instructional design and technology, where developmental studies are being seen as the right way to advance direction in the discipline. In fact, Reeves et al. (2005) observed that developmental research can contribute to the field as it can inform the field of instructional design "as it may well advance the quality and usefulness of a field that is presently at risk of becoming inconsequential and irrelevant" (p. 110) through the ineffective media comparison studies. Actually, Reeves (2000) pointed out that "if educational technologists want to be more socially responsible, they should pursue developmental goals" (p. 24). So, the framework comes to be of essential relevance and importance to the field of 
instructional design and technology as it provides a model for the use of theory to drive effective instructional practice.

The literature reviewed did indicate that situated cognition provides a more authentic learning experience (Brown et al., 1989; Collins, 2006; Collins, Brown \& Newman, 2007; CTGV, 1990). The present framework has been created to inform future teaching of English as an L2 in Malawi. The literature also identified the gap that while situated strategies have shown to improve teaching in various areas throughout the world, those strategies are not in use in Malawi especially in the English as an L2 classroom (Harley, 1991; Herrington \&. Oliver, 2000; Griffin \& Griffin, 1996; Lave, 2008; Mondada \& Doehler, 2004). To that end, a different way to teach English as a second language more meaningfully in Malawi has been identified based on the literature. The features contained in the framework have been derived from situated cognition and they serve to contextualize the teaching of various topics in English language and grammar. This, in essence, proposes a solution to a problem where teaching of English as an L2 in Malawi is to a large extent being done using strategies that do not enable learners to seamlessly close gap between what they learn and how those skills would be used in real life outside of the classroom. So, essentially, conduct of the study supports the creation of the framework informed by the literature and guided by input of educational experts and practitioners who will be employing these strategies.

\subsection{Limitations}

The framework has been predominantly developed to be used in Malawi. From the analysis phase, its development was guided by views and practices of English methodology faculty members in Malawi's five secondary school teacher training institutions. For example, the eight faculty members emphasized the importance of developing the framework around the four language skills; listening, reading, writing and speaking. To that end, there was deliberate effort in the development process to vary content in the examples used in the framework across these important four skills in language teaching. Furthermore, learning materials and aides used in the examples are typically Malawian including literary genre pieces, names of places and so on. It must further be pointed out that views from English methodology practitioners on the potential challenges the framework would face in Malawi were also taken into consideration in its development. For these reasons, the framework is to a large extent good for use in Malawi but may work in other countries with minor modifications.

\section{References}

Altalib, H. (2002). Situated cognition: Describing the theory. (Report No. ED 475 183). Retrieved from ERIC database.

Blatner, A. (2002). Role Playing in education. Retrieved from http://www.blatner.com/adam/pdntbk/rlplayedu.htm

Bonk, C. J., \& Reynolds, T. H. (2007). Learner-centered Web instruction for higher-order thinking, teamwork, and apprenticeship. In B. H. Khan (Ed.), Web-based Instruction (pp. 167-178). Englewood Cliffs, NJ: Educational Technology Publications.

Bransford, J. D., Sherwood, R. S., Hasselbring, T. S., Kinzer, C. K., \& Williams, S. M. (1990). Anchored instruction: Why we need it and how technology can help. In D. Nix \& R. Spiro (Eds.), Advances in computer-video technology, computer, cognition, and multi-media: Explorations in high technology (pp. 115-142). Hillsdale, NJ: Lawrence Erlbaum Associates.

Brown, J.S. (2006). New learning environments for $21^{\text {st }}$ century: Exploring the edge. Change: The Magazine of Higher Learning, 38(5), 18-24. http://dx.doi.org/10.3200/CHNG.38.5.18-24

Brown, J.S., Collins, A., \& Duguid, S. (1989). Situated Cognition and the Culture of Learning. Educational Researcher, 18(1), 32-42. http://dx.doi.org/10.3102/0013189X018001032

Bwanali, A. K. (2002, September 18). How much English must we know? The Nation. Retrieved from http://www.mwnation.com

Cognition and Technology Group at Vanderbilt (CTGV). (1990). Anchored instruction and its relationship to situated cognition. Educational Researcher, 19(6), 2-10. http://dx.doi.org/10.3102/0013189X019006002

Collins, A. (2006). Cognitive apprenticeship and instructional technology (Report No. 68990). Cambridge, MA: Cambridge University Press.

Collins, A., Brown, J. S., \& Newman, S. E. (2007). Cognitive apprenticeship: Teaching the crafts of reading, writing, and mathematics. In L.B. Resnick (Ed.), Knowing, learning and instruction: Essays in honor of Robert Glaser 
(pp. 453-494). Hillsdale, NJ: Lawrence Erlbaum Associates.

Fraenkel, Wallen, \& Hyun (2015). How to Design and Evaluate Research in Education (9th Ed.). New York, NY: McGraw-Hill.

Gabrys, G., Weiner, A., \& Lesgold, A. (2007). Learning by problem solving in a coached apprenticeship system. In M. Robinowitz (Ed.), Cognitive science foundations of instruction (pp. 119-147). Hillsdale, NJ: Lawrence Erlbaum Associates.

Glaser, B.G., \& Strauss, A. L. (2012). The discovery of grounded theory: Strategies for 154 qualitative research. Chicago: Aldine Publishing Company.

Griffin, M.M. (1995). You can't get there from here: Situated learning, transfer and map skills. Contemporary Educational Psychology, 20, 65-87. http://dx.doi.org/10.1006/ceps.1995.1004

Griffin, M. M., \& Griffin, B.W. (1996). Situated cognition and cognitive style: Effects on students' learning as measured by conventional tests and performance assessments. Journal of Experimental Education, 64(4), 293-308. http://dx.doi.org/10.1080/00220973.1996.10806600

Harley, S. (1991). A study of situated cognition for third and fourth grade students doing math word problems (Unpublished doctoral dissertation). Ohio State University, Ohio.

Harley, S. (1993). Situated learning and classroom instruction. Educational Technology, 33(3), 46-51.

Herrington, J., \& Oliver, R. (2000). An instructional design framework for authentic learning environments. Educational Technology Research and Development, 48(3), 23-48. http://dx.doi.org/10.1007/BF02319856

Kamwendo, G.H. (2007a). English in Malawi education system: The present and the future. English Today, 14(3), 75-84.

Kamwendo, G.H. (2007b). Language rights in the dictatorship: The case of Malawi during Dr. Banda's rule. Language Matters, 28(1), 36-50. http://dx.doi.org/10.1080/10228199708566119

Kamwendo, G.H. (2008). Is Malawi guilty of spoiling the Queen's language? English Today, 19(2), 30-33. http://dx.doi.org/10.1017/S0266078403002062

Kayambazinthu, E. (2008a). The role of English in Malawi: Achievements and prospects in English at the turn of the millennium. Language Matters, 22(2), 39-47.

Kayambazinthu, E. (2008b). .The language planning situation in Malawi. Journal of Multilingual and Multicultural Development, 19(5), 369 -439. http://dx.doi.org/10.1080/01434639808666363

Krajcik, J.S., \& Blumenfield, P.C. (2006). Project-based learning. In K. Sawyer (Ed.), The Cambridge handbook of the learning sciences (pp. 317-333). New York, NY: Cambridge University Press.

Lave, J. (2008). Cognition in practice: Mind, mathematics, and culture in everyday life. (2nd Ed.). Cambridge: Cambridge University Press.

Lave, J., \& Wenger, E. (2003). Situated cognition: Legitimate peripheral participation. Cambridge, MA: Cambridge University Press.

Littlewood, W. (2009). Communicative language teaching. New York, NY: Cambridge University Press.

Loberger, G., \& Welsh, K.S. (2009). Webster's new world English grammar handbook. New York, NY: Hungry Minds.

McLellan, H. (1993). Evaluation in a situated learning environment. Educational Technology, 33(3), 39-45.

Ministry of Education (MOE). (2014). A report on the deteriorating standards of education in Malawi. Zomba, Malawi: Government Printers.

Mondada, L., \& Doehler, S.P. (2004). Second language acquisition as situated Practice: Task accomplishment in the French second language classroom. The Modem Language Journal, 88(4), 501-518. http://dx.doi.org/10.1111/j.0026-7902.2004.t01-15-.x

National Statistics Office (NSO). (2008). Malawi population census: Final report. Zomba: Government Printers.

Nave, A. (2009). Malawi. In K.A. Appiah \& H.L. Gates Jr. (Eds.), Africana: The encyclopedia of the African and African-American experience (pp. 1229-1232). New York, NY: Basic Civitas Books.

Reeves, T.C. (2000). Socially Responsible Educational Technology Research. Educational Technology, 40(6), 19-28. 
http://dx.doi.org/10.1007/BF02961476

Reeves, T.C., Herrington, J., \& Oliver, R. (2005). Design Research: A socially responsible approach to instructional technology research in higher education. Journal of Computing in Higher Education, 16(2), 96-115. http://dx.doi.org/dx.doi.org/10.1007/BF02961476

Resnick, L. (1987). Learning in school and out. Educational Researcher, 16(9), 13-20. http://dx.doi.org/dx.doi.org/10.2307/1175725

Richards, J. C., \& Rodgers, T. S. (2001). Approaches and methods in language teaching. Cambridge language teaching library. Cambridge: Cambridge University Press.

Richey, C.R., \& Klein, J.D. (2010). Design and development research. Mahwah, New York, NY: Routledge.

Russ-Eft, D., \& Preskill, H. (2009). Evaluation in organizations. New York: Basic Books.

Strauss, A., \& Corbin, J. (2015). Basics of qualitative research techniques and procedures for developing grounded theory (2nd Ed.). London: Sage Publications.

Swick, E. (2014). Practice makes perfect: English grammar for ESL learners. New York, NY: McGraw-Hill Companies, Inc.

Sroka, K.A. (2007). The syntax of English phrasal verbs. Paris: The Hague.

United Nations Educational, Scientific and Cultural Organization (UNESCO). (2003). The use of vernacular languages in education. Paris: UNESCO.

Van Ments, M. (2007). The effective use of role-play: A handbook for teachers and trainers. London: Kogan Page Ltd.

Weaver, C. (2006). Teaching grammar in context. Portsmouth, NH: Boynton/Cook.

Wenger, E. (2008). Communities of practice: Learning, meaning, and identity. New York, NY: Cambridge University Press.

Winn, W. (1993). Instructional design and situated learning: Paradox or partnership? Educational Technology, 41(1), 43-58.

Witkin, B.R., \& Altschuld, J.W. (2007). Planning and conducting needs assessment. CA: Sage Publications, Inc.

Young, M. F. (1993). Instructional design for situated learning. Educational Technology Research and Development, 41(1), 89-96. http://dx.doi.org/10.1007/BF02297091

Young, M.F. (1995). Assessment of situated learning using computer environments. Journal of Science Education and Technology, 4(10), 89-96. http://dx.doi.org/http://dx.org/1007/BF02211586 